\title{
For the Cuban Dead
}

Once they were men fully because they belonged, and everywhere they looked and chatted and sipped a bit of coffee, whisked away a fly with a wrist or jolted a newspaper readably straight, or flirted, or worried about the world and where the damn country was going as a trolley rolled and curtains dipped and bulged breast-like and hid again in the proper window. They were home and citizens of it and dared and loved and were decent and stole and killed and loved again. They were home. How like the root in the earth, the crease in the linen, the wind rending the cloud, the growl in the hunger, the pavement sprayed with waves crashing against the sea wall. How like all right things in the mind of place, they jostled and failed, learned and betrayed. Like coins in pockets made for them they cried stridently or simply tinkled in murmurs, and it didn't matter if talk or life had substance. Right of place was substance.

There is no enough in exile. Not enough anger, and the blanket of safety always leaves the feet bare. And it is here, no matter how clean and golden, that one learns how different the wrist and the fly and the shot of wave, how once never stops calling although the law of distance deafens. Memory is the heart's gravity.

The accent of their children becomes unbearably alien, a dampness from the sidewalk creeping past the thin sole and into the ignored sock. Now nothing escapes notice and the balance is always against. 
And it hits them, these never again composed, that the time to see and hear was then, when rightness held even the stormy evils of the quotidian in the same palm with the trash of years of seconds and the kissed joys.

Then, as we have come to know, was the proper place to gaze at the dust of butterfly panoplies, ponder the calligraphic crud on china, relinquish decorous ears to taut goatskins, wash in the lace of Sunday clouds, and otherwise pay attention with one's whole life to shadows knitting five centuries of incomparable capital, field's antique jewel, and the cradling shore.

God it was who let them die filled with late understanding, so who dares say we the innocent lurk unpunished in the works and days?

RICARDO PAU-LLOSA

"For the Cuban Dead" is taken from Pau-Llosa's collection Parable Hunter (Pittsburgh: Carnegie Mellon UP, 2008). The poem first appeared in Crab Orchard Review and was also included in Burnt Sugar/Caña quemada, ed. Lori Marie Carlson and Oscar Hijuelos (New York: Free Press, 2006). 